Indian J. Anim. HIth. (2019), 58(2) : 147-156

DOI: https://doi.org/10.36062/ijah.58.2.2019.147-156

Review Article

\title{
POSTNATAL CALF MORTALITY- A REVIEW
}

\author{
A. MANDAL*, K. PATHAK, M. KARUNAKARAN AND M. K. GHOSH \\ ICAR-National Dairy Research Institute \\ Eastern Regional Station \\ Kalyani-741 235, West Bengal, India
}

\begin{abstract}
Calf mortality is one of the important problems of calf rearing in dairy farms worldwide. Successful cattle production system encompasses the ability to develop healthy calves for both in economic and animal welfare points of view. Generally, early calf mortality reduces the replacement stock in any herd and thus it causes genetic loss due to reduced possibility of selection, and thereby yielded less genetic gain. Various published literature showed significant influences of environmental factors on calf mortality. As the environmental factors are dynamic in nature, so determination of the effect of these factors on calf mortality is required for obtaining the reliable estimates for this trait. Moreover, existed additive genetic variation for mortality needs to be estimated for effecting the improvement of this trait. One possible way of improving calf survivability is to include this trait as a selection criterion in breeding programmes. To do this, the genetic component for this trait must be studied.
\end{abstract}

Key words: Calf mortality, Correlation studies, Environmental factors, Genetic parameters

The survivability of calf is an important trait both for breeding and economic point of view in dairy enterprise. A high rate of calf mortality not only reduces farm income but also affects the number of animals available for selection, thus reducing selection intensity and genetic progress. Therefore, mortality in dairy calves has great relevancy in terms of economic losses and also for animal health and welfare (FuerstWaltl and Sorensen, 2010). In dairy production system, female calves are generally kept as replacement animals and male calves are kept/ sold for breeding purpose. High calf mortality rate may delay the progress in replacing cull cows or increasing the herd size. It might consequently result in a shortage of replacement heifers and a need to buy animals that further increases the replacement costs of the herd (Torsein et al., 2011). Calf mortality at birth is generally occurred due to calving difficulties

*Corresponding author 
and health problems of the cows. The productivity of the herd can be reduced due to low survival rate of calf at birth and at subsequent ages of development. High calf mortality in any herd limits the genetic selection and increases the chance of acquisition of replacement stock in dairy animals. In tropical areas, where zebu cattle are predominant, calf mortality before weaning is high and accounts for almost a third of calf crop losses (Wells et al., 1996). Death rate in dairy calves in the first 16 weeks of life in temperate climates varies considerably among herds, but usually ranges from $8 \%$ to $12 \%$ (Torsein et al., 2011). As the postnatal mortality (PM) of calves is a major issue related to animal health and welfare, so considering the increasing concern on animal health and welfare worldwide, these aspects should be considered in future animal breeding strategies (Olesen et al., 2000). Thus, necessary measures can be taken by improving management factors and by improving the genetic factors deciding the ability of the calf to survive. It is thus necessary to integrate calf survival traits in the definition of an overall breeding objective in cattle.

\section{Prevalence of calf mortality}

The mortality of calves is to a large degree dependent on the management, and large variations in calf morality are observed between farms and production systems. The highest risk in calf mortality is generally observed during the first 3 weeks of life (Wells et al., 1996). Calf mortality during calving and after parturition (within the first 24-48 $\mathrm{h}$ after birth) is termed as perinatal mortality and it mainly occurs due to dystocia (Gundelach et al., 2009). Fuerst-Waltl and Sorensen (2010) investigated calf loss in Danish Holstein cattle and they found mortality rates of $3.23 \%, 2.66 \%$ and
$0.97 \%$ for the period of day 1-30, day 31-180 and day 181-365, respectively. Sheikh (2010) observed the average survivability of Jersey crossbred calves was of $89.77 \%$ and the maximum number of calves died during birth to 15 days of age (5.68\%) followed by $3.40 \%$ and $1.14 \%$ during $15-30$ and 30-60 days of age, respectively. Van Pelt et al. (2012) reported that survival rate of $97.5 \%$ from $15-180$ days in dairy calves raised for veal production. Norberg et al. (2013) found an increased postnatal mortality rate of $12.5 \%$ within the first 180 days in Danish Jersey heifer calves. Chaudhary et al. (2013) reported the highest mortality of $21.53 \%$ in calves followed by young stocks $9.35 \%$ and adults $4.73 \%$. Among the three age groups, calves had highest mortality (16.09\%) due to poor management problems followed by $2.48 \%$ cases of digestive diseases. Mishra et al. (2015) reported that the overall mortality percentage in 1-3 and 3-6 months of age groups were $3.61 \%$ and $2.41 \%$, respectively and these values were $3.14 \%$ and $1.64 \%$ for male and female calves, respectively. The highest $(5.44 \%)$ mortality rate was observed within 1 month of birth in both the sexes (Mishra et al., 2015). They stated that the age period of 0-1 month is the most crucial stage of the calf life and after this period, the chances of survival of calves get maximized. Kharkar et al. (2017) reported the overall mortality rate was $31.22 \%$, with the maximum percentage $(15.12 \%)$ of calves died within one month of age after birth in Jersey $x$ Sahiwal crosses. Further, they observed that the overall mortality percentage during 1-3 month, 3-6 month and 6-12 months of age groups were $5.75 \%$ (7.06\% in male and $4.49 \%$ in female), $6.10 \%(5.06 \%$ in male and $7.06 \%$ in female calves), and $8.44 \%$ (12.00\% in male and $5.06 \%$ female calves), respectively. 


\section{Causes of calf mortality}

Calf mortality is a multifactorial problem, the management of the herd, the dam and the season all have an impact. The major causes of calf mortality can be classified as infectious and non-infectious. The infectious causes are diarrhoea and pneumonia caused by bacteria, viruses and protozoa. The major non-infectious causes are dystocia, improper feeding of colostrum, low birth weight and poor management practices. Dystocia is the main cause of calf mortality and about 50 percent of calf mortality occurs due to dystocia. McCorquodale et al. (2013) stated that the two most frequent diseases affecting calves are diarrhea and respiratory disease. Torsein $\mathrm{et} \mathrm{al}$. (2011) also reported that the gastrointestinal disorders and pneumonia were the two main causes of calf mortality during the first month of life and these causes were influenced by housing conditions, colostrum intake and feeding management of calves. Rao and Nagarcenkar (1980) observed that high percentage of calf mortality was due to respiratory diseases from birth to 1 month of age in crossbred cattle while diseases affecting the digestive system resulted in more deaths in the 3 to 6 months age group. Islam et al. (2005) observed pneumonia as the main cause of mortality in calves. The causes for mortality in crossbred calves were evaluated by Verma $\mathrm{et} \mathrm{al}$. (1996). According to them, the maximum mortality occurred due to tympany problem accounting for $1.36 \%$ followed by septicemia problem $(0.83 \%)$ and hepatitis problem $(0.80 \%)$. They suggested that timely and required amount of colostrum feeding to neonatal calves resulted into lower incidences of death. Balvir et al. (2009) observed the gastro-enteritis $(7.30 \%)$ as major causes of mortality followed by pneumonia and others. Mishra et al. (2015) reported that the maximum mortality in Gir calves was due to gastroenteritis $(6.18 \%)$, which was due to bacterial or viral infections, or due to delayed feeding of colostrum to the calves. In this study, pneumonia was the second important reason of calf mortality with $3.16 \%$ followed by other causes (viz. insufficient or delayed colostrum feeding, handling causes, worm infestation, snake bites etc), which resulted in $3.65 \%$. Kharkar et al. (2017) reported the highest mortality in calves was due to gastroenteritis $(32.81 \%)$ followed by pneumonia $(18.75 \%)$, other $(15.63 \%)$ and septicaemia $(12.50 \%)$ in Jersey $\times$ Sahiwal crosses. Pathak et al. (2018) also reported that the highest mortality in calves occurred due to gastroenteritis / calf scour / diarrhea $(43.26 \%)$ followed by respiratory disease (mainly pneumonia) $(22.74 \%)$, Congenital defect / premature birth (10.87\%), digestive disorders (viz. bloat, tympany etc.) (6.04\%), injury / accidental fall (5.63\%) and others $(16.70 \%)$ in Jersey crossbred calves.

\section{Factors affecting the calf mortality}

The following non-genetic and genetic factors significantly influence the mortality patterns of calves at different ages:

\section{A. Effect of non-genetic factors on calf mortality}

Effect of period of birth : Several authors reported that the period of birth significantly influences the mortality patterns of calves at different ages in different breeds of cattle and its crosses. Gunawan et al. (2013) found the significant effect of year of birth on survival(\%) of calf at weaning in Bali cattle. Mishra et al. 
(2015) also obtained significantly variation in mortality rate in calves born in different birthperiods. Kharkar et al. (2017) found the significant effect $(\mathrm{P}<0.05)$ of birth-year on the mortality rate in Jersey $\times$ Sahiwal crossbred calves. However, Kumar et al. (2002) reported non-significant effect of period of birth on mortality from birth to 12 month of age in Jersey crossbred cattle. Shahi and Kumar (2014) also observed the non-significant effect of period on mortality from 3-6 month and 612 months in Jersey $\times$ Sahiwal crosses.

Effect of parity of dam: Various published reports (Van Pelt et al., 2012; Gunawan et al., 2013; Norsberg et al., 2013; Mishra et al., 2015) stated that parity of dam significantly affected the mortality of calves of different cattle breeds at pre and postnatal stages of life. Van Pelt et al. (2012) obtained the decrease trend in calf mortality with increasing parity number, reaching the lowest level at ninth parity and higher. Norberg et al. (2013) found that the mortality risk of calves increased with increasing age (parity) of dam in Jersey cattle. Mishra et al. (2015) observed that the overall mortality rate in first, second, third and fourth or more parities was $7.17 \%, 4.54 \%, 1.40 \%$ and $2.84 \%$, respectively and these variations were statistically significant $(\mathrm{P}<0.05)$. On contrary, Hansen et al. (2003), Gulliksen et al. (2009) and Kharkar et al. (2017) observed nonsignificant effect of parity of dam on calf mortality at various ages in Norwegian Red, Holstein and Jersey $\times$ Sahiwal crossbred cattle, respectively.

Effect of season of birth: Season of birth is considered as an important factor in determining the risk of mortality of calves. Published reports (Kumar et al., 2002; Bleul,
2011; Kharkar et al., 2017; Kumar et al., 2017) showed that season of birth played significant influence on calf mortality at pre-and postweaning stages in different purebred and crossbred cattle. Kumar et al. (2002), Gulliksen et al. (2009), McCorquodale et al., (2013) and Mellado et al. (2014) reported the highest mortality of calves in winter season in different cattle breeds. The increased mortality rate of calves in winter season may be due to exposure to cold temperatures on calf mortality (Kumar et al., 2002), production of lower quality colostrum during the winter months (Shearer et al., 1992)) or due to the impaired absorption of immunoglobulins from colostrum (Beam et al., 2009). Kharkar et al. (2017) observed the highest mortality in winter season $(40.30 \%)$ followed by monsoon $(36.47 \%)$ and summer $(11.32 \%)$ seasons. On the other hand, Henderson et al. (2011) reported that risk of mortality was largely constant across seasons of birth. Kumar et al. (2002) in Jersey crossbred and Singh and Gurnani (2003) in Karan Fries cattle and Shahi and Kumar (2014) in Jersey $x$ Sahiwal crosses found non-significant effect of season of birth on mortality rate of calves.

Effect of sex of calves: Significant differences in mortality rate of calves between sexes have been published in literature for various cattle breeds. The calf mortality rate in different breeds of cattle was significantly higher $(\mathrm{P}<0.05)$ in males than their female counterparts as reported by Dhakal et al. (2013) and Mellado et al. (2014). Pathak et al. (2018) also reported the similar line of research finding in Jersey crossbred cattle. Research finding of calf mortality indicated that the heavy birth weight of male calf compared to its counterpart accounted for the high male calf mortality (Johanson and Berger, 2003). This increased 
calf weight may cause a mismatch of fetal maternal size, which increases the occurrence of dystocia, and calves under these circumstances are more prone to die.

Effect of birth weight of calves: Size of calves at birth is an important factor for calving ease of the dams and neonatal survival of the calves (Johanson and Berger, 2003). The increased birth weight of calves is associated with calving problems like dystocia and stillbirths and ultimately it leads to calf mortality. Johanson and Berger (2003) reported that the higher birth weight of calves was associated with increased perinatal calf mortality and dystocia in dairy cattle. The calf characteristics such as calf vigour (Riley et al., 2004), birth weight, birth type (single or twin) and the occurrence of dystocia are well recognised factors influencing calf survival across a range of breeds and production environments. The association between birth weight and survival is non-linear and both low and high calf birth weights are problematical for calf survival. Riley et al. (2004) reported that poor birth vigour and low birth weights were correlated with elevated rates of calf mortality within the Brahman breed, potentially due to reduced colostrum intake, which has implications for both early survival and ongoing immunity. Bleul (2011) reported that the calf weight at birth had significant $(\mathrm{P}<0.05)$ influence on perinatal morality in some cattle breeds. Henderson et al. (2011) found that calves having birth weight of 38 to $41 \mathrm{~kg}$ had more chance to survive than calves in lighter or heavier weight groups. McCorquodale et al. (2013) observed that calf weight at 0 to 8 days of age had significant $(\mathrm{P}<0.05)$ effect on a calf's risk of mortality. Lower birth weight of calves was associated with higher calf mortality. Bunter et al. (2013) reported that low birth weight itself was associated with increased calf mortality rates, particularly within the first week and month after birth. Ibi et al. (2015) observed the mortality rate of Japanese Black calves in each risk period and they reported that lighter birth weight was associated with higher postnatal mortality, although extremely heavier birth weight tended to be associated with higher postnatal mortality, especially in the early stage. Pathak et al. (2018) observed the significant $(\mathrm{P}<0.01)$ effect of birth weight on calf survivability in Jersey crossbred animals and they reported that calves' having birth weight of $\leq 15 \mathrm{~kg}$ were at an increased risk of mortality, whereas calves weighing birth weight of more than $30 \mathrm{~kg}$ were at a decreased risk of mortality.

Effect of level of exotic inheritance in calves: Rao and Nagarcenkar (1980) studied the mortality rate of crossbred calves having different exotic inheritance level and reported that the mortality rate was the lowest in halfbreds than the crosses with $75 \%$ exotic inheritance of temperate breeds. Laster and Gregory (1973) reported that breeding group influenced calf mortality in parturitions involving dystocia, but did not significantly influence calf mortality in unassisted parturitions. Calf losses in dystocia parturitions ranged from $6.6 \%$ for Jersey $\times$ Angus to $28.8 \%$ for straight-bred Herefords. However, genetic group did not significantly influence the neonatal calf mortality in first or later parities in Holstein, Jersey and crossbred cows (Dhakal et al., 2013). Similarly, Pathak et al. (2018) obtained non-significant effect of genetic group on calf mortality at different ages in Jersey crossbred calves. 


\section{B. Effect of genetic factor on calf mortality}

Pathak et al. (2018) observed significant $(\mathrm{P}<0.05)$ sire effect on calf survivability percent at day 31-90, 91-180 and 181-365. The significant effect of sire on calf survivability at different ages indicates this trait may be improved genetically through selection of sires.

\section{Genetic parameters estimates}

Calf mortality is a binary or "all or none" trait. Either the calf is dead or alive ( 0 or 1$)$ in a given time period, and therefore it is a categorical variable. Various studies (Hansen et al., 2003; Fuerst-Waltl and Sorensen, 2010) have shown that survival of calves is different at different stages of life and may be controlled by different genes. Therefore, calf mortality at different ages of the rearing period can be defined as separate traits.

\section{Heritability estimates of the mortality traits:} Published literature demonstrated that the heritability estimates of calf mortality at different ages were mostly low in magnitude in different breeds of cattle. The estimate of direct heritability for pre-weaning mortality (survival to 24 or $48 \mathrm{~h}$, or perinatal mortality) ranged from 0.02 to 0.15 in cattle (Koots et al., 1994; McGuirk et al., 1998). The estimate of maternal heritability of survivability traits of calves was of low in magnitude as reported by different workers (Koots et al., 1994; Goyache et al., 2003) in various studies. Hansen et al. (2003) estimated the direct heritabilities for four mortality traits i.e. D1-14, D15-60, D61-180, and D1-180, which ranged from 0.001 to 0.008 . Maternal heritabilities were reported as very low, ranging from 0.0002 to 0.0015 and were significant for D1-14 and D1-180 only. Considering the calf mortality as a trait of the calf and without inclusion of maternal effects, Guerra et al. (2006) estimated the heritabilities for calf mortality by different statistical models and they observed that the heritability estimate by linear model was low (0.05) but it was moderate by threshold $(0.16)$ and logistic model (0.19) in a multi-breed population. Henderson et al. (2011) found a very small heritability (0.0006) for mortality from day 1 to weaning when applying a linear model. Direct heritabilities for mortality of calves were estimated in 8 different periods, from $24 \mathrm{~h}$ after birth to age 180 days (d 1-14, d 15-30, d 3160, d 61-90, d 91-120, d 121-150 and d 151-180) and mortality over the entire period (d 1-180) by Norberg et al. (2013) and they found the estimates were quite low, ranging from 0.002 to 0.03 on the observable scale and 0.025 to 0.076 on the underlying scale. Maternal heritabilities were estimated to be very small and insignificant, which indicates that the dam's role in calf mortality is genetically less important than the direct effect (Norberg et al., 2013). Heritability of a binary trait estimated with linear models is frequency dependent, and low frequency could result in low heritability (Eaglen et al., 2012). In Iranian Holstein cattle, heritability estimates of mortality were very low ranging from 0.48 to 3.04 for linear sire model, 0.62 to 3.51 for animal model and 0.50 to $4.24 \%$ for threshold sire model, respectively as reported by Forutan et al. (2015). Common for all studies is that the heritability estimates were very low $(<0.10)$ in dairy cattle and the observed low heritabilities were mainly due to a low frequency of calf mortality, large environmental variation and different causes of death.

Correlation estimates: Several authors investigated the genetic relationships between 


\section{Genetic aspects of calf mortality}

calf mortality at early life and late life as these early life mortality and late life mortality is probably two different traits (Hansen et al., 2003; Fuerst-Waltl and Sorensen, 2010). In a study, Fuerst-Waltl and Sorensen (2010) found a genetic correlation of 0.92 between the period from 31-180 days and 181-365 days. Hansen et al. (2003) reported genetic correlations of 0.73 between day 1-14 and day 15-60, 0.54 between day 25-60 and 61-180 and low correlations of 0.34 between day 1-14 and day 61-180. Henderson et al. (2011) found a genetic correlation of 0.58 between survival from arrival date to weaning and from weaning to exit from the heifer facility. Van Pelt et al. (2012) found a high genetic correlation (0.85) between the two traits i.e. day 3-14 (all calves) and day 3-365 (heifer calves), but a moderate genetic correlation (0.66) between day 3-365 (heifer calves) and day 15-180 (veal calves). In Jersey heifer calves, Norberg et al. (2013) found a genetic correlation of 0.88 between mortality from day 1 to 14 and day 1 and 180, as the first 14 days are the same in both time periods, it is expected that there is a high correlation. These results substantiate that there is a genetic difference between early life mortality and mortality later in the rearing period and it could potentially be different groups of genes that are

\section{REFERENCES}

Balvir S, Brijesh S, Ghosh AK, Yadab SN, Singh SK et al., 2009. Causes of mortality among Red Sindhi cattle at organized herd. Indian J Anim Prod Manage, 24(3-4): 20-22

Beam AL, Lombard JE, Kopral CA, Garber LP, Winter AL et al., 2009. Prevalence of failure responsible. Estimates of genetic correlations by Forutan et al. (2015) for survival between different age periods (viz., 31-180 and 181365 days), (31-180 and 366-760 days) and (181-365 and 366-760 days) obtained from the bivariate linear sire model were $0.59,0.52$ and 0.42 , respectively. The low genetic correlations obtained among mortality of calves at different ages may indicate that mortality of calves in the early and late age periods was controlled by different genes.

\section{Conclusions}

Calf mortality is one of the major problems in dairy farms worldwide. The first three months of calves are the most crucial period for survivability of calves in any dairy farm. Different environmental factors played significant role on most of the survivability traits of calves which indicates the optimum standardization of calf rearing and management practices are needed in the farm for better survivability of calves. Moreover, these traits can be improved genetically through selection of superior sires. Low heritability estimates of survivability traits indicate very slow genetic progress by selection and thus survivability of calves could be improved by better management practices.

of passive transfer of immunity in newborn heifer calves and associated management practices on US dairy operations. J Dairy Sci, 92(8): 3973-3980

Bleul U, 2011. Risk factors and rates of perinatal and postnatal mortality in cattle in Switzerland. Livest Sci, 135: 257-264 
Bunter KL, Johnston DJ, Wolcott ML and Fordyce G, 2013. Factors associated with calf mortality in tropically adapted beef breeds managed in extensive Australian production system. Anim Prod Sci, 54(1): 50-59

Chaudhary JK, Singh B, Prasad S and Verma MR, 2013. Analysis of morbidity and mortality rates in bovine in Himachal Pradesh. Vet World, 6(9): 614-619

Dhakal K, Maltecca C, Cassady JP, Baloche B, Williams CM et al., 2013. Calf birth weight, gestation length, calving ease, and neonatal calf mortality in Holstein, Jersey, and crossbred cows in a pasture system. J Dairy Sci, 96: 690-698

Eaglen SAE, Coffey MP, Woolliams JA and Wall E, 2012. Evaluating alternate models to estimate genetic parameters of calving traits in United Kingdom Holstein-Friesian dairy cattle. Genet Sel Evol, 44: 23

Forutan M, Ansari Mahyari S and Sargolaei M, 2015. Genetic evaluation of calf and heifer survival in Iranian Holstein cattle using linear and threshold models. J Anim Breed Genet, 132: 51-58

Fuerst-Waltl B and Sorensen MK, 2010. Genetic analysis of calf and heifer losses in Danish Holstein. J Dairy Sci, 93(11): 5436-5442

Goyachea F, Gutie’Rrezb JP, Alvareza I, Fernandez I, Royoa LJ et al., 2003. Genetic analysis of calf survival at different preweaning ages in beef cattle. Livest Prod Sci, 83: 13-20

Guerra JLL, Franke DE and Blouin DC, 2006. Genetic parameters for calving rate and calf survival from linear, threshold, and logistic models in a multibreed beef cattle population. J Anim Sci, 84: 3197-3203
Gulliksen SM, Lie KI, Loken T and Osteras O, 2009. Calf mortality in Norwegian dairy herds. J Dairy Sci, 92: 2782-2795

Gunawan A, Jakaria J and Parwoto Y, 2013. Genetic and non-genetic effect on gestation length and calf survival at weaning in Bali cattle. Jurnal Ilmu Produksi danTeknologi Hasil Peternakan, 1(3): 179-183

Gundelach Y, Essmeyer K, Teltscher MK and Hoedemaker M, 2009. Risk factors for perinatal mortality in dairy cattle: cow and foetal factors, calving process. Theriogenology, 71: 901-909

Hansen M, Madsen P, Jensen J, Pedersen $\mathbf{J}$ and Christensen LG, 2003. Genetic parameters of postnatal mortality in Danish Holstein calves. J Dairy Sci, 86: 1807-1817

Henderson L, Miglior F, Sewalem A, Kelton D, Robinson A et al., 2011. Estimation of genetic parameters for measures of calf survival in a population of dairy calves in New York, state. J Dairy Sci, 94(1): 461-470

Islam SS, Ahamed AR and Ashraf A, 2005. Causes and consequences of calf mortality in a dairy farm of Bangladesh. J Anim Vet Adv, 4(2): 260-264

Johanson JM and Berger PJ, 2003. Birth weight as a predictor of calving ease and perinatal mortality in Holstein cattle. J Dairy Sci, 86: 3745-3755

Kharkar KP, Raghuwanshi DS, Lende S and Khati BM, 2017. Mortality pattern in crossbred calves of dairy cattle. J Krishi Vig, 5(2): 116121

Koots K, Gibson J, Smith C and Wilton J, 1994. Analyses of published genetic parameter 


\section{Genetic aspects of calf mortality}

estimates for beef production traits. 1. Heritability. Anim Breed Abst (U. K), 62: 309-338

Kumar CR, Moorthy PRS, Rao KS and Naidu KV, 2002. Calf mortality pattern in relation to age and sex in organized livestock farms in Andhra Pradesh. Indian J Anim Sci, 72(10): 921-923

Kumar NC, Gaur GK, Sahoo SP, Devi LS and Tripathi AK, 2017. factors affecting growth and mortality pattern of Tharpakar calves at organised dairy farm. J Livest Res, 7(5) : 87-92

Laster DB and Gregory KE, 1973. Factors influencing peri and early postnatal calf mortality. J Anim Sci, 37(5): 1092-1097

Ibi T, Kahi AK and Hirooka H, 2015. Genetic parameters of postnatal mortality and birth weight in Japanese Black calves. Anim Sci, 86(1): $25-30$

McCorquodale CE, Sewalem A, Miglior F, Kelton D, Robinson A et al., 2013. Short communication: analysis of health and survival in a population of Ontario Holstein heifer calves. J Dairy Sci, 96: 1880-1885

McGuirk BJ, Going I and Gilmour AR, 1998. The genetic evaluation of UK Holstein Friesian sires for calving ease and related traits. Anim Sci, 68: 413-420

Mellado M, Lopez E, Veliz FG, De Santiago MA, Macias-Cruz U et al., 2014. Factors associated with neonatal dairy calf mortality in a hot-arid environment. Livest Sci, 159: 149-155

Mishra AK, Rawat NS, Nanawati S and Gaur AK, 2015. Studies on the calf mortality pattern in Gir breed. Int J Livest Prod, 6(4): 47-51
Norberg E, Pryce J and Pedersen J, 2013. Short communication: A genetic study of mortality in Danish Jersey heifer calves. J Dairy Sci, 96(6): 4026-4030

Olesen I, Groen AF and Gjerde B, 2000. Definition of animal breeding goals for sustainable production systems. J Anim Sci, 78: 570-582

Pathak K, Koloi S, Ghosh MK, Karunakaran MK and Mandal A, 2018. Genetic analysis of calf survivability in crossbred cattle. Indian $\mathbf{J}$ Dairy Sci, 71(6): 598-603

Rao MK and Nagarcenkar R, 1980. Calf mortality in crossbred dairy cattle. Trop Anim Hlth Prod, 12: 137-144

Riley DG, Chase Jr CC, Olson TA, Coleman SW and Hammond AC, 2004. Genetic and nongenetic influences on vigor at birth and preweaning mortality of purebred and high percentage Brahman calves. J Anim Sci, 82: 1581-1588

Shahi BN and Kumar D, 2014. Studies on mortality and culling rate among female calves of Sahiwal and Jersey crossbred cattle. Indian J Vet Anim Res, 43(6): 454-457

Shearer J, Mohammed HO, Brenneman JS and Tran TQ, 1992. Factors associated with concentrations of immunoglobulins in colostrum at the first milking post-calving. Prev Vet Med, 14: 143-154

Sheikh IU, 2010. Influence of non-genetic factors on birth weight, sex ratio and survivability of crossbred jersey calves. Asian J Bio Sci, 5(2): 192-194

Singh MK and Gurnani M, 2003. Factors affecting disposal trends in crossbred cattle at closed organized farm. Indian J Anim Sci, 73: 296-299 
Torsein M, Lindberg A, Sandgren CH, Waller KP, Tornquist M et al., 2011. Risk factors for calf mortality in large Swedish dairy herds. Prev Vet Med, 99(2-4): 136-137

Van Pelt M, Eding H, Vessies P and De Jong G, 2012. Developing a genetic evaluation for calf survival during rearing in The Netherlands. Interbull Bulletin, 46: 61-65
Verma A, Nagpal PK, Tomar OS and Verma A, 1996. Effect of feeding fresh preserved colostrum on mortality, incidences of diarrhea and body weight of crossbred calves. Indian J Anim Prod Manage, 12(2): 69-72

Wells SJ, Dargatz DA and Ott SL, 1996. Factors associated with mortality to 21 days of life in dairy heifers in the United States. Prev Vet Med, 29: 9-19 